\title{
Definición teórica de las características del ci- berperiodismo: elementos de la comunicación digital
}

Javier Díaz Noci

Profesor de Periodismo de la Universidad del País Vasco

Resumen:

El estudio del ciberperiodismo, como nuevo medio de comunicación, exige una investigación teórica básica que permita, en primer lugar, definir con claridad los conceptos y características que definen el nuevo fenómeno. En este artículo hacemos un recorrido por los postulados teóricos de esos conceptos: hipertextualidad, interactividad, multimedialidad y memoria. Hacemos también referencia a las corrientes metodológicas empleadas para su medición y estudio. La conclusión es que nos encontramos frente a un nuevo medio con nuevas características que, correctamente definidas, pueden ser observadas empíricamente, lo que nos permitirá establecer las correspondientes tipologías genéricas.

Palabras clave:

Ciberperiodismo. Hipertextualidad. Interactividad. Multimediadlidad. Memoria.

Abstract:

Studying cyberjournalism (online journalism), as a new medium, must be firmly based on a basic theoretical research in order to define clearly the concepts and characteristics that define that new phenomena. In this article, we explain the theory and trends around those concepts: hypertext, interactivity, multimedia language and memory. We also refer to the methodological currents used to measure and study those characteristics. As a conclusion, we defend that we are in front 
of a new medium with new characteristics which, correctly defined, could be empirically observed, and so we could also establish the generical typologies.

Key words:

Online journalism. Hypertext. Interactivity. Multimedia. Memory.

\section{Introducción}

El estudio del periodismo en Internet, o, más ampliamente, lo que hemos dado en llamar ciberperiodismo $^{1}$, es una disciplina que, como el propio fenómeno que analiza, apenas tiene más de una década. Cumplida ya esa década de ciberperiodismo, y de investigación del ciberperiodismo, nos parecía un buen momento para hacer balance de qué es lo que se ha hecho y qué tendencias, metodologías y temas se han priorizado en este tiempo. A nuevos problemas, nuevos métodos de análisis. Es lo que, en las acertadas palabras del profesor Elias Machado, es una “inversión de las prioridades” y el "desafío de la investigación aplicada” frente a una nueva realidad o, incluso, un nuevo paradigma (Machado, 2003).

Buena parte de los conceptos diferenciales, aunque vienen de antes, son igualmente novedosos. Pensamos, por tanto, que es necesario identificar y definir esos conceptos que hacen del discurso periodístico digital un objeto de estudio diferente del de otras manifestaciones periodísticas. Sólo así podremos establecer tipologías propias, si las hay, o investigar en toda su dimensión esta nueva forma de hacer periodismo. Obviamente, no hay nada completamente nuevo bajo el sol. Por eso, nos ha parecido conveniente dedicar un buen espacio a tratar de estas cuestiones de investigación básica, teórica, fijándonos en las aportaciones que sobre estos conceptos y características llevan ya algún tiempo haciéndose desde otros campos del saber: la lingüística, la psicología, los estudios literarios, la historiografía o la semiótica. Más que nunca, creemos que es necesario conocer esas corrientes teóricas y metodológicas y suscitar un diálogo con esas disciplinas humanas y sociales si queremos analizar con corrección y de forma lo más completa posible el ciberperiodismo.

1 Para una definición de este concepto, véase la Introducción al Manual de redacción ciberperiodística. 
Este trabajo intenta explicar las principales características que la comunidad académica internacional ha discernido como propias del discurso digital: la hipertextualidad, la interactividad, la multimedialidad, a las que se pueden añadir otras, como la memoria o la dimensión temporal. Son características que provocan, o están en trance de hacerlo, profundas, aunque paulatinas y prudentes, modificaciones en la forma que el ser humano tiene de transmitir conocimientos a sus semejantes. También nos fijaremos en los cambios que se están produciendo en el receptor, en el lector. El proceso comunicativo es siempre un diálogo entre varias partes, un intercambio de información, pero no sólo de datos.

Se trata de dar continuidad a un trabajo de años en el que hemos intentado, y continuamos haciéndolo ${ }^{2}$, desbrozar un camino investigador que, con el tiempo, se revela sólido y que va dando sus frutos.

\section{Un nuevo medio: el ciberespacio}

La hipótesis principal que formulamos es que estamos frente a un nuevo medio, y por tanto el canal obliga a adaptar la producción informativa a las características del mismo. Determinar cuáles son esas características es indispensable si se quiere hacer cualquier tipo de teorización sobre los géneros ciberperiodísticos que han comenzado a forjarse, algunos de los cuales son bien diferentes de los que ya conocemos en la prensa escrita o los medios audiovisuales. Entre otras cosas, porque muchas de esas características son imposibles de conseguir en los medios que hasta ahora conocíamos.

Las características generales del medio digital serían, siguiendo a Lev Manovich (Manovich, 2005: 72):

1. La representación numérica, o digitalización, que vuelve a los nuevos medios programables. Se trata de la característica que con más precaución aborda Manovich, por considerarlo ambiguo ya que, en su opinión, se trata de un término global para designar tres conceptos sin relación entre sí: la conversión de lo analógico a lo digital (la

\footnotetext{
Este artículo es parte de los trabajos desarrollados para los proyectos de investigación EHU06/32, de la Universidad del País Vasco, y SEJ2006-14828-C06-02 del Ministerio de Educación y Ciencia.
} 
digitalización propiamente dicha); la existencia de un código de representación común; y la representación numérica.

2. La modularidad, o "estructura fractal de medios". Es decir, los medios están compuestos por muestras discretas, con un fuerte énfasis en la estructura.

3. La variabilidad, o sea, la posibilidad de que el mensaje no esté fijado de una vez por todas, sino que pueda ser presentado y recuperado en diferentes versiones. Se trata de una característica que deriva de la modularidad. La variabilidad permite también la personalización y la actualización de los contenidos. Asimismo, hace posible la escalabilidad, o presentar versiones diferentes del mismo objeto mediático con diversos niveles de detalle.

4. La automatización de muchas operaciones de creación, manipulación y acceso a la información. La arquitectura de la información, y en última instancia, las investigaciones en inteligencia artificial, son resultado de estos procesos.

5. La transcodificación, lo que implica un cambio a, junto las estructuras y convenciones tradicionalmente establecidas por los humanos, otras estructuras propias de la organización de los datos por el ordenador.

Si el ciberperiodismo es aquella variedad de la actividad profesional de conseguir y ofrecer información de actualidad mediante medios informáticos para ofrecerla en el ciberespacio, una buena definición de este último concepto es la de Lucia Santaella, para quien ciberespacio es "todo aquel espacio informativo multidimensional que, dependiente de la interacción del usuario, permite a éste el acceso, la manipulación, la transformación y el intercambio de sus flujos codificados de información [...], espacio que se abre cuando el usuario se conecta a la red [...] hecho de circuitos informativos navegables" (Santaella, 2004: 45).

El ciberespacio es, como ha dejado dicho Rafael Royo, "un estado de percepción determinado" (Royo, 2004), donde el lector, o usuario, ha desarrollado ya un nuevo modelo de interacción con la información (que se refleja, por ejemplo, en los modos de lectura ya identificados) y donde se enfrenta a códigos y lenguajes nuevos. Hay varios libros en castellano que también 
se refieren específicamente a la cuestión, como los de Isidro Moreno (Moreno, 2002) o MarieLaure Ryan (Ryan, 2004) y que nos arrojan luz sobre los caminos que han de seguir los cibertextos informativos. En primer lugar, se trata de superar la visión no sólo lineal, sino también plana del medio.

Se trataría de determinar hasta qué punto las estructuras poseen las cualidades semánticas de los discursos, basada en la interpretación en relación con otros elementos del texto. En el caso del cibertexto, dichos elementos son los nodos, y los mecanismos de unión, los hipervínculos. El texto periodístico, como cualquier otro texto, no es una representación estricta y directa de la realidad, sino un artefacto, un hecho lingüístico fabricado. Van Dijk propone que existen estructuras generales o macroestructuras y microestructuras. Pensamos que puede hacerse lo mismo con respecto a las estructuras hipertextuales de los discursos ciberperiodísticos, de los, si se quiere, cibertextos. Son de la misma opinión los investigadores italianos Gianfranco Bettetini, Barbara Gaspirini y Nicoletta Vittadini, quienes recuerdan que "el hipertexto puede leerse como macrotexto compuesto de microtextos, conectados entre sí en un mapa-laberinto explorable por el usuario" (Bettetini et al., 1999: xiii-xiv). La estructura se rige según un ars combinatoria que tiene relación con el concepto de grupo, usado en matemática y lógica.

La teoría sobre el hipertexto ha progresado hasta determinar una serie de estructuras típicas (Toschi, 2001; Powell, 2001: 98; López et al., 2002, 2002; Codina, 2002: 301-316; Díaz Noci, Salaverría, 2003; Rovira, 2002a y 2002b; Carvalho, 2005) que en principio serían de aplicación a las informaciones periodísticas. Éstas se dividen en axiales o reticulares. La mayoría de los diarios digitales se limita a proponer noticias que constan de dos nodos vinculados entre sí, sin retorno: un resumen de la noticia que consta de un titular (habitualmente en funciones de hipervínculo), una entradilla o enganche (teaser), a veces una fotografía y, en su caso, el pie de foto, que se desarrolla en un nodo que ofrece toda la información completa, desarrollada, y que muy a menudo repite el titular y el primer párrafo utilizado total o parcialmente para esa entradilla o enganche.

En cuanto a las características principales del nuevo medio, parece haber un acuerdo en la comunidad científica en que son la hipertextualidad, la multimedialidad y la interactividad. 
Son las tres características que, al menos para los cibermedios de la primera generación, enumera Mark Deuze (Deuze, 2001). La mayoría de los autores añaden algunas características más, que son las que vamos a ver a continuación. Por ejemplo, una dimensión temporal, que incluye fenómenos como la sincronía y la asincronía (antes los medios debían optar generalmente por una de las dos, en Internet ambas son posibles), la renovación continua de la información, mediante sustitución (el llamado "efecto palimpsesto") o mediante acumulación, o la tempestividad, o período de tiempo en que resulta oportuno que las informaciones permanezcan en la Red o se vinculen con otras informaciones posteriores. También se habla de actualización. Y así, por ejemplo, para saber si los medios se han convertido en cibermedios (ellos se fijan en el caso gallego), el equipo del profesor Xosé López, de la Universidad de Santiago de Compostela (López et al., 2005), añaden a las tres características clásicas, la frecuencia de actualización y el contenido.

\begin{tabular}{|c|c|}
\hline \multicolumn{2}{|c|}{ Cuestionario de cibermedialidad: variables para el análisis } \\
\hline \multirow[t]{4}{*}{ Hipertextualidad } & 1. Adecuación a la estructura de los contenidos. \\
\hline & 2. Jerarquización de la navegación. \\
\hline & 3. Profundización en los hechos. \\
\hline & $\begin{array}{l}\text { 4. Comprensibilidad de la organización hipertextual de } \\
\text { la información. }\end{array}$ \\
\hline \multirow[t]{4}{*}{ Multimedialidad } & 5. Adaptación a la naturaleza de los contenidos. \\
\hline & 6. Versatilidad de los recursos multimedia. \\
\hline & 7. Adecuación del formato. \\
\hline & 8. Inexistencia de duplicidad narrativa. \\
\hline \multirow[t]{3}{*}{ Interactividad } & 9. Acomodo a la necesidad de feedback de los contenidos. \\
\hline & 10. Posibilidad de personalizar la información. \\
\hline & $\begin{array}{l}\text { 11. Justa relevancia de las réplicas del internauta en la } \\
\text { configuración del discurso informativo. }\end{array}$ \\
\hline
\end{tabular}




\begin{tabular}{|l|l|}
\hline \multirow{4}{*}{ Frecuencia de actualización } & 12. Contacto “útil" del usuario con el medio. \\
\cline { 2 - 3 } & 13. Adaptación a la necesidad real de renovación de los \\
\hline \multirow{5}{*}{ Contenido } & contenidos. \\
& 14. Garantía de sedimentación del mensaje periodístico. \\
\cline { 2 - 2 } & 15. Ampliación y/o renovación de contenidos (nunca \\
\cline { 2 - 2 } & corrección). \\
& 16. Diferente tratamiento periodístico de la información \\
\hline \multirow{5}{*}{$\begin{array}{l}\text { de portada respecto de la edición impresa. } \\
\text { 17. Enriquecimiento de la información de portada }\end{array}$} \\
\cline { 2 - 2 } & $\begin{array}{l}\text { mediante las potencialidades del soporte telemático } \\
\text { (en comparación con la edición impresa). }\end{array}$ \\
\hline
\end{tabular}

Fuente: López et al., 2004, p. 626.

En un artículo publicado en 2004, Elías Machado, Clarissa Borges y Milena Miranda, investigando los medios del estado de Bahía, en Brasil, proponen además la memoria (Machado et al., 2004). Del mismo procede Marcos Palacios, quien establece cinco características: la multimedialidad/convergencia, la interactividad, la hipertextualidad, la personalización y la memoria, a la que añade una sexta, la actualización continua (Palacios, 2002).

Por nuestra parte, proponemos los siguientes criterios para establecer una primera tipología de los cibertextos periodísticos, que esquematizamos en las siguientes tablas: 


\begin{tabular}{|c|c|}
\hline \multicolumn{2}{|c|}{ Criterios de clasificación retórica } \\
\hline Topoi & Partes del discurso \\
Géneros narrativos & Inventio: Multilinealidad y poliacroasis \\
Géneros interpretativos & Dispositio: Estructuras hipertextuales \\
Géneros dialógicos & Actio: Interactividad \\
Géneros argumentativos & Elocutio: Recursos multimedia \\
& Memoria \\
\hline
\end{tabular}

\begin{tabular}{|c|c|c|c|}
\hline \multicolumn{4}{|c|}{ Recursos hipertextuales } \\
\hline \multicolumn{2}{|c|}{ Enlaces } & \multicolumn{2}{|c|}{ Estructuras } \\
\hline 1. Según el destino: & 2. Según el propósito: & Tipo & Grado \\
\hline a. Externo / Interno & a. Estructurales & Axial & * Profundidad \\
\hline b. De conexión entre & i. Jerárquicos & a. Lineal & (número de niveles) \\
\hline aplicaciones & ii. Semánticos & b. Arbórea & * Número de \\
\hline c. De comando & b. Explícitos/Implícitos & c. Paralela & itinerarios por nivel \\
\hline d. Unirrelación / & c. Unidireccionales / & Reticular & \\
\hline Multirrelación & Bidireccionales & & \\
\hline e. De desplazamiento & d. Planos / definidos & & \\
\hline
\end{tabular}

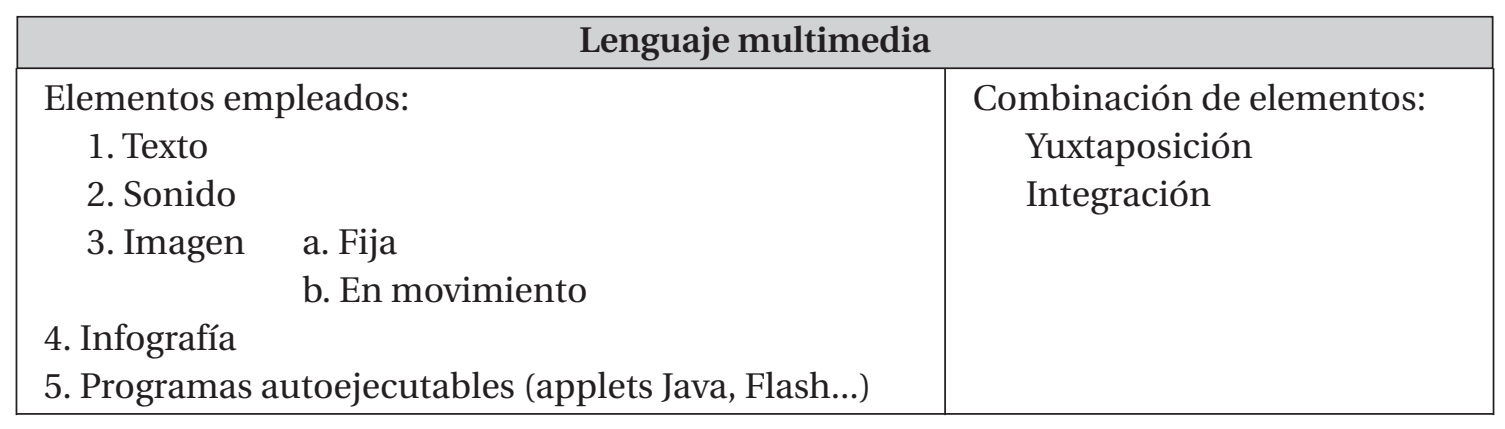




\begin{tabular}{|c|c|c|c|c|}
\hline \multicolumn{5}{|c|}{ Interactividad y participación } \\
\hline $\begin{array}{l}\text { Tipo de } \\
\text { interactividad }\end{array}$ & $\begin{array}{l}\text { Grado de } \\
\text { dialogismo }\end{array}$ & Temporalidad & Técnica & $\begin{array}{l}\text { Intervención } \\
\text { del medio }\end{array}$ \\
\hline $\begin{array}{l}\text { - Inclusiva } \\
\text { (periodismo de } \\
\text { código abierto) } \\
\text { - Autorial } \\
\text { Estructuras } \\
\text { resultantes } \\
\text { - Aleatorias } \\
\text { - Fijas } \\
\text { - Relacionales } \\
\text { - Contributivas }\end{array}$ & $\begin{array}{l}\text { - Simétrico } \\
\text { - Uno a uno } \\
\text { - Muchos a } \\
\text { muchos } \\
\text { - Asimétrico } \\
\text { - Uno a muchos } \\
\text { - Muchos a } \\
\text { muchos }\end{array}$ & $\begin{array}{l}\text { - Sincronicidad } \\
\text { - Asincronicidad }\end{array}$ & $\begin{array}{l}\text { a) Dialógicas } \\
\text { - Correo } \\
\text { electrónico } \\
\text { - Foro } \\
\text { - } \\
\text { - SMS } \\
\text { b) Personalización } \\
\text { - Búsqueda en } \\
\text { base de datos } \\
\text { - Configuración de } \\
\text { la interfaz }\end{array}$ & $\begin{array}{r}\text { - Moderación } \\
\text { - Ausencia de } \\
\text { moderación } \\
\text { Chat }\end{array}$ \\
\hline
\end{tabular}

\begin{tabular}{|c|c|}
\hline \multicolumn{2}{|c|}{ Temporalidad y tempestividad } \\
\hline Temporalidad & Tempestividad \\
$\bullet$ Sincronismo & - Permanencia \\
• Asincronismo & $\bullet$ Periodo \\
& $\bullet$ Renovación continua \\
& $\bullet$ Por acumulación \\
& $\bullet$ Por sustitución \\
\hline
\end{tabular}

Vamos a explicar con algo más de detalle: la hipertextualidad, la interactividad, la memoria y arquitectura de la información, y la multimedialidad y recuperación de la información. 


\section{Hipertexto periodístico}

Una buena definición de hipertexto, en nuestra opinión, es la que dan María Teresa Vilariño y Anxo Abuín González en la introducción al libro colectivo Teoría del hipertexto. La literatura en la era electrónica: "El hipertexto [...] es un tipo de texto interactivo, no secuencial, no lineal (o multi-lineal), esto es, no basado en una secuencia fija [...] cuya secuencialidad pueda variar considerablemente a lo largo de la lectura" (Vilariño y Abuín, 2006: 20).

Esto contrasta, desde luego, con el concepto fuertemente lineal de la narratología de Mieke Bal (Bal, 1998: 60-61). Lo que parece claro es que se necesita una narratología propia del hipertexto. Una narrativa que distinga, como hace David Crystal, entre el texto interrumpido y el texto no lineal, aquel que "puede ser leído de un modo multidimensional" (Cristal, 2001: 196197). No conviene, en cambio, muestra otras debilidades, en opinión de los investigadores británicos Roy Rada y Clare Murphy (Rada y Murphy, 1992): en su intento por diferenciar claramente el hipertexto del texto, a menudo se ha presentado este último como un producto estereotipado. Por ejemplo, se ha exagerado la desaparición del autor, o la dimensión colaborativa en el hipertexto.

Otra definición de hipertexto sería la que propone Marina Vianello: "El hipertexto es un entorno lógico para la adquisición de la información, la organización del conocimiento, la lectura y la escritura, que permite desestructurar los textos tradicionales, emulando y exteriorizando el funcionamiento de la mente, que opera por asociaciones. Esta estructura permite al lector transformar la lectura en un acto que implica la reescritura del texto y su interpretación personal frente a la totalidad de la información potencialmente disponible” (Vianello, 2004: 327).

En la actualidad, los hiperdocumentos que pueden encontrarse en la World Wide Web se acercan al modelo ideal cuyas características enunció en 1987 J. Conklin:

1) Ser una base de datos en red compuesta por nodos textuales y/o gráficos.

2) Dichos nodos se ven en la pantalla del ordenador en forma de ventanas. Sólo puede verse un número determinado de ventanas en la pantalla.

3) Las ventanas se manejan de forma estándar: abrir, cerrar, desplazarse. 
4) Los nodos contienen enlaces a otros nodos de la base de datos.

5) El usuario puede crear nuevos nodos o modificar los existentes.

6) Una base de datos puede visualizarse de tres maneras:

a. Siguiendo los enlaces.

b. Mediante búsquedas por palabras clave.

c. Mediante un mapa gráfico de la red de conexiones.

El hipertexto es, como recuerdan Gianfranco Bettitini, Barbara Gaspirini y Nicoletta Vittadini, un constructo teórico cuyas características fundamentales son la organización modular y reticular del contenido, la presencia de diversas tipologías de vínculos que conectan los módulos; la ausencia de una dirección de lectura única y obligada; la interactividad, explicitada en una modalidad doble de navegación y dialogismo. Estos investigadores italianos conciben el hipertexto como un espacio que comprende una lectura entres niveles, que componen la dimensión comunicativa del mismo: la organización de los contenidos, la prefiguración de las dinámicas de recuperación y la visibilidad de ambas.

La estructura de nodos y, sobre todo, enlaces, es la que ha recibido probablemente más atención por parte de los investigadores. Especialmente, las estructuras no lineales, abiertas, arbóreas, son las que han recibido más atención por parte de quienes estudian el hipertexto desde el punto de vista de la teoría literaria. Otra aproximación es la que se hace a la interfaz, lo que en el fondo, según Daniel Cunliffe (Cunliffe, 2000), distingue a los sistemas de hipertexto de las bases de datos. La investigación sobre las interfaces se ha centrado en las metáforas de navegación, en los mecanismos de control por parte del usuario y en el comportamiento durante la navegación. Lo examinaremos con más detalle en los apartados dedicado a la memoria y a la multimedialidad.

Si hablamos de semiótica, resulta obligado hablar de los autores italianos, para empezar, del propio Umberto Eco. En su Estructura ausente, Eco recuerda que una parte del análisis semántico es de las estructura narrativas: Propp, Todorov, Greimas, Barthes, Levi-Strauss, Genette o Morin se han ocupado de ellas. Y ello conduce inevitablemente a la retórica. Una po- 
sible vía retórica para el análisis de las estructuras hipertextuales es la aplicación del modelo Quillian, o modelo Q, "que se basa en una masa de nudos interconectados entre sí por diferentes tipos de vínculos asociativos”, un modelo que además prevé la incorporación de nuevas informaciones (se trata de un modelo creativo. Se trataría de ver si existen "sistemas de reglas” o, en el caso que nos atañe, el del hipertexto periodístico, se tiende a funcionar, como en la enseñanza de la redacción periodística, "por repertorios de ejemplos o modelos de comportamiento" (Eco, 1977: 199, 222).

También Massimo Maietti (Maietti, 2004) ha realizado una aproximación semiótica al texto interactivo. Estudiar el documento hipertextual como una relación producción-lectura, lo que denomina isomorfismo de las teorías hipertextuales y las examina a la luz de las teorías cognitivas. Propone la confección de mapas hipertextuales, examinando los diagramas de flujo, pero también el denominado "espacio lógico", remitiéndose así a Espen Aarseth y su noción topológica de la no linealidad hipertextual (Aarseth, 1997, 2003), que es, según la organización W3, puesta en marcha por el inventor de la World Wide Web, Tim Berners-Lee, la característica fundamental de ese sistema hipertextual. También recuperar el concepto de "ambiente", como resultado de la densidad espaciotemporal de los hipertextos, donde son centrales conceptos como el punto de vista, simulacro, interfaz, es decir, todos aquellos en que el usuario, como agente social, es parte de la red hipertextual (su "posición textual”, empírica, y no sólo las referencias al autor y el lector modelos), y pierde peso en cambio la aproximación tradicional de las unidades discretas de información.

Habría, así, tres niveles de estudio en el modelo de M. Maietti:

1) El nivel de la interfaz.

2) El nivel de la función atribuida al usuario, al jugador. Cabría recordar aquí la posibilidad de imbricación de la teoría del hipertexto con la teoría de juegos (Díaz Noci, 2002), como estrategia social. Maietti estudia las estructuras de los videojuegos, pero también la aplicabilidad de una teoría hipertextual que contemple diversos aspectos de una manera más universal. Y, por lo que se refiere al ciberperiodismo, creemos que convendría pro- 
fundizar en los aspectos lúdicos e inmersivos (un "simulacro explorativo", si se quiere) de las informaciones hipertextuales.

3) La estructura hipertextual, evitando una nueva falacia, que las estructuras más reticulares, y por tanto menos jerárquicas, son más apropiadas para representar la actividad cognitiva de los usuarios, frente a la direccionalidad de estructuras axiales, de las cuales Maietti presenta la arbórea como la más típica.

Investigadores como Jean Climent (Climent, 1995) se han referido a las figuras retóricas del discurso hipertextual. Enumera fundamentalmente tres: la sinécdoque, la asíndeton y la metáfora. En el primer caso, la sinécdoque (tomar la parte por el todo) significa en el caso del hipertexto que el fragmento (el nodo, la escena hipertextual) se toma por el hiperdocumento en su totalidad. Es, al contrario que en el texto impreso, una figura dinámica: con cada nodo -recordemos: coherente en sí mismo- el lector tiende a imaginar el todo, pero cada nuevo nodo hacia el que avanza le obliga a reconfigurar la visión conjunta del hiperdocumento que va descubriendo. Se trataría, por tanto, de una figura exploratoria.

La asíndeton, figura que consiste en la supresión del término de unión entre dos proposiciones, se trasladaría al hipertexto en el sentido de que cada nodo "flota" en la pantalla, sin unión evidente, o realizada por el momento, con el o los otros nodos de la estructura. Eso nos lleva de nuevo a considerar la cualidad lírica de los enlaces.

Finalmente, la metáfora permite, según Clément, que cada nodo se presente a los lectores en función de los itinerarios para los que fue escrito. Es decir: su coherencia, por decirlo de otra manera, se construye igualmente en función de una coherencia superior. Se trata de una figura especialmente ensalzada por la teoría cognitiva, que la considera el principal mecanismo por el que se comprenden los procesos abstractos, conceptuales.

Otro autor que ha reivindicado la retórica como perspectiva descriptiva de estudio del hipertexto ha sido Espen Aarseth (Aarseth, 1997b). Incluso la que considera característica más importante del hipertexto, la no linealidad, como una figura retórica, pero no como un tropo. Dentro de la no linealidad pueden englobarse la bifurcación, los enlaces y saltos, la permutación, la computación y la poligénesis. La bifurcación es la figura más simple y evidentemente 
no lineal; según Jay David Bolter, toda bifurcación es una hipérbaton. Los enlaces son, según Aarseth, las figuras más relevantes del hipertexto, que funcionan a nivel sintáctico, puesto que separa y ordena las unidades de información, las lexias. Las lexias pueden ser, según Manuel Gago, unidades mínimas dependientes o unidades mínimas interdependientes, según el nivel de autonomía con respecto al contexto que ofrezcan. Se trata de una distinción no sólo técnica, sino también de coherencia textual. Sí, en los cibermedios, indica Gago, "una unidad mínima de contenido contiene un valor relacional determinado". Con ello se consigue "incrementar la profundidad [...], favorecer las posibilidades de personalización del usuario [y] reducir costes de elaboración de contenido", es decir, se favorece una concepeción modular de la información periodística (Gago, 2006: 114-116).

Por lo tanto, la estructura, como organización cognitiva y referencial, es un elemento muy importante en la propuesta de Luiz Marcuschi (Marcuschi, 1999, 2000), quien, por ejemplo, se refiere a investigaciones sobre la coherencia hipertextual como respuesta a los intereses de los lectores, y a la generación de secuencias mediante una distribución jerárquica arbórea, una distribución en forma de lista o de forma lineal tradicional. Se trata de una investigación llevada a cabo por D. Dee-Lucas en 1996, que arrojó unos resultados bien interesantes:

1) La estructura arbórea es más rápida y fácil, siempre que se especifique un criterio de búsqueda claro.

2) Las listas provocan un acceso más lento y difícil.

3) El texto lineal tradicional arrojó una búsqueda de calidad, pero aún más lenta.

Igualmente, a mayor segmentación, la búsqueda es más lenta pero más segura, de forma que el número de equívocos disminuye. Y es aquí, precisamente, donde entra en juego el concepto de coherencia. De nuevo, es preciso recordar las teorías de Martin Engebretsen (Engebretsen, 1997, 2001) sobre la coherencia intranodal, internodal e hiperestructural. O, como ha dejado dicho Stuart Moulthrop, por una parte los cibertextos son estructuras de ruptura pero, por otra, son obras en continuidad, "en consonancia con las pautas y ritmos de las industrias de la información” (Moulthrop, 1997). 
No podemos terminar este epígrafe sin referirnos a algunas críticas a las diferentes aproximaciones teóricas al hipertexto. Un autor norteamericano, Alex Soojung-Kim Pang, dibujaba en 1998 cuál era el panorama de las investigaciones sobre hipertexto. Tras referirse, como suelen hacer todos los trabajos de este tipo (véanse, por ejemplo, los primeros epígrafes del capítulo 2 del Manual de redacción ciberperiodística), a los pioneros del hipertexto, Soojung-Kim expone cuáles son las fortalezas y debilidades de la teoría del hipertexto. Por ejemplo, halla que determinadas estructuras y estrategias del mundo impreso -por ejemplo, la búsqueda y lectura de artículos de enciclopedias- se refuerzan mediante el hipertexto. Domenico Fiormonte, filólogo italiano, ha puesto de manifiesto que "los lenguajes de marcación [...] imitan la 'realidad textual' concentrándose sobre todo en sus estructuras jerárquicas”, a pesar de la "concepción dinámica del texto [mobile text]" (Fiormonte, 2002). Para Fiormonte, se ha producido un desplazamiento del autor y el texto único, del producto, en definitiva, al proceso. Domenico Fiormonte es partidario de una nueva ciencia del texto que sea "una reflexión seria sobre los instrumentos específicos de la producción [y] las diversas estructuras de comunicación contenidas en la obra multimedia” (Fiormonte, 1998: 266-267). Está de acuerdo Javier Echeverría, para quien "el hipertexto rompe con algunos de los principios básicos de la escritura impresa, por ejemplo con la linealidad del significante, la contextualidad o la noción del discurso. El hipertexto permite accesos transversales a la información y el conocimiento, no secuenciales [...]. Frente a las estructuras verticales y encajadas de las Summae del saber [...] el hipertexto impone una estructura reticular" (Echevarría, 2002).

Por su parte, Bettetini, Gasparini y Vittadini han puesto de manifiesto las limitaciones de lo que denominan la "escuela estadounidense", a cuya cabeza se encontraría George Landow, que parte de la teoría literaria y la psicología cognitivista. Frente a ello, proclaman la primacía de la "escuela franco-italiana", que prefiere analizar el fenómeno hipertextual desde el punto de vista semiótico. A la misma escuela milanesa pertenece Carlos Scolari, quien ha dejado escrito que "la investigación de la interactive fiction debería seguir otros recorridos", por ejemplo, fijándose en los videojuegos (Scolari, 2000).

Por lo que se refiere al periodismo, autores como David Domingo se han referido al contraste entre las posibilidades teóricas del hipertexto y el uso real que se hace de él, bastante más sen- 
cillo (Domingo, 2006: 414). De mismo modo que Stuart Moulthrop, que como ya hemos visto se mostraba realista frente al discurso revolucionario del hipertexto y la resistencia que a la hora de la verdad se hace a aquellos que muestran un mayor grado de desarrollo y complejidad, que provocan un mayor desbordamiento cognitivo del "espacio de decisión”, y un abuso de la deconstrucción, Domingo indica que buena parte de la práctica periodística en la Web no ha cumplido las utopías previstas. Las noticias de actualidad (breaking news) no han desarrollado, por lo general, estructuras hipertextuales complejas. Como mucho, se plantean estructuras paralelas a la lineal principal.

Y es que, como recuerda el profesor Marcos Palacios (Palacios, 2005), Natura non facit saltum, y por tanto, el paso del periodismo impreso al periodismo hipertextual ha potenciado, mucho más que en la literatura de ficción -de la que proviene buena parte de la teoría del hipertexto que hemos examinado- lo que ya había de multilineal y de lectura transversal en los medios que conocíamos, en vez de acogerse a todas las posibilidades teóricas que brinda el hipertexto.

Finalmente, Susana Pajares Tosca (Pajares, 2003) se ha referido a esa supuesta crisis de los estudios del hipertexto (al menos, el hipertexto literario). Las estructuras hipertextuales se han convertido, por habituales, en invisibles o transparentes. Por eso, Pajares Tosca propone, como ya están haciendo otros autores, estudiar la organización de los hipertextos en bases de datos, la gestión automática de éstos (la interactividad), la dimensión temporal o la multimedialidad.

\section{La interactividad}

El concepto de interactividad está aún lejos de ser unívoco. Tal es su importancia, que de este rasgo del discurso digital se derivan otros igualmente a tener en cuenta, como la personalización de contenidos, la inmersividad o incluso la democratización de la información; es la interactividad la que hace que se pase del paradigma de la comunicación de masas (emisor único, receptor igualmente único aunque compuesto de individuos diferentes, constructo ideal condicionado por la tecnología) al paradigma de la comunicación multilateral, donde 
la pluralidad de agentes está sujeta a múltiples variaciones y hace posible, si se permite la metáfora, una presentación caleidoscópica y polifónica. Es la interactividad, asimismo, la que está provocando profundas mudanzas en la autoría de la información: el autor no es sólo quien propone el texto, sino que éste se completa, cambia, o sustituye por la intervención del lector. La propia estética de la recepción debería ser, por lo tanto, replanteada.

Se trata, para empezar, de una palabra ("interactividad") no siempre reconocida por los diccionarios. Desde luego, cuenta con más tradición el término “interacción”. Jorge Lozano, Cristina Peña-Marín y Gonzalo Abril recuerdan que "el discurso no está constituido solamente por un conjunto de proposiciones, sino también, y fundamentalmente, por una secuencia de acciones", es decir, "los procesos discursivos pueden ser vistos como secuencias de actos o recorridos narrativos". Si nos fijamos en la narratología (del texto) "el análisis de las acciones cuenta con una unidad sintáctica mínima, el programa narrativo". Aún más, "las acciones se organizan en secuencias dotadas de un orden lógico, y los programas accionales secundarios se articulan jerárquicamente en un programa narrativo global” (Lozano, Peña-Marín, Abril, 1998: 248-250).

"Interacción" es el que prefiere también Carlos Scolari, en su libro Hacer clic. La narrativa hipertextual sería, por lo tanto, una propuesta realizada en entornos colaborativos que precisan de la interacción para ser finalmente materializados.

Charo Sádaba define la interactividad como "la potencialidad de un sistema tecnológico de favorecer procesos comunicativos eficientes al permitir la presencia de elementos que hacen análoga la comunicación mediada por la tecnología al diálogo" (Sádaba, 2000), y distingue entre la comunicación entre un usuario y un ordenador y la comunicación entre personas, aunque mediada por la técnica. Por su parte, Alejandro Rost insiste en su trabajo alrededor de dos tipos de interactividad: la selectiva (“interacción con los contenidos”), la comunicativa ("interacción entre individuos") y una combinación de ambas ("interacción con los contenidos y entre individuos"). Así, define la interactividad como "la capacidad gradual y variable que tiene un medio de comunicación para darle a los usuarios/lectores un mayor poder tanto en la selección de contenidos (interactividad selectiva) como en las posibilidades de expresión y comunicación (interactividad comunicativa)" (Rost, 2006: 1995, 285-300, 353-358). 
Las aproximaciones al estudio de la interactividad son diversas y, a veces, contrapuestas. Hay quien considera que la interactividad es el resultado de la lectura hipertextual, y quien piensa que va más allá. Así, Marie-Laure Ryan que "la forma prototípica de textualidad interactiva (aunque de ningún modo la más interactiva)" es el hipertexto (Ryan, 2004: 22). Esta postura vincula el estudio de la interactividad al del hipertexto y éste a las corrientes de la estética posmoderna representada por Barthes, Derrida, Foucault, Kristeva, Deleuze y Guattari, para el texto, y a Landow, Bolter, Joyce y Moulthrop, para el hipertexto. Marie-Laure Ryan distingue dos aproximaciones conceptuales a la interactividad: aquella que describe "la colaboración entre el lector y el texto en la producción de significado”, es decir, la que correspondería al hipertexto exploratorio, y otro tipo de interactividad, la que permite al usuario controlar la dinámica del hiperdocumento como despliegue de signos. Mientras el primer tipo de interactividad sólo permite escoger entre alternativas predeterminadas -es la que corresponde a la lectura de un hiperdocumento siguiendo determinados itinerarios pulsando los enlaces propuestos- el segundo tipo obliga al lector a participar en la producción de sentido, es una actividad mucho más creadora. Le exige, por lo tanto, una inmersión en el texto. El primer tipo de interactividad se denomina selectiva, y el segundo tipo de interactividad se llama productiva.

Uno de los trabajos indispensables para comprender el concepto de interactividad en la comunicación es el de Hanssen, Jankowski y Etienne (Hanssen et al., 1996). Para ellos la interactividad tiene que ver con el grado de participación de los agentes en el proceso comunicativo, y la posibilidad que tienen de introducir cambios en el mismo. Distinguen tres niveles de interactividad: el más alto, entre personas y cara a cara; el segundo, entre personas y medios que ofrecen la posibilidad de recuperar contenidos $\mathrm{y}$, hasta cierto punto, manipularlos; el tercero, más bajo, sólo permite recuperar información, sin ninguna oportunidad para el usuario de introducir cambios en la misma. Rafaeli, por su parte, distingue tres niveles de interactividad: comunicación bidireccional (no interactiva), comunicación reactiva (quasi interactiva) y comunicación completamente interactiva. Un trabajo anterior, de 1986, de Bordewijck y Van Kaan, mencionaba cuatro tipos más simples de interactividad: la de transmisión, que simplemente permite activar o cancelar una emisión, por ejemplo de 
radio o televisión; la de consulta, que permite al usuario escoger una opción de un menú; la conversacional, que además permite enviar mensajes a otros usuarios (los foros o el chat); y la de registro, que permitiría una mayor personalización, puesto que las características del usuario, obtenidas mediante ese sistema de registro, permiten al sistema ofrecer la información que se ajuste a su perfil.

Los tipos fundamentales de interfaz son, según Xosé Pereira, dos, que a su vez tienen relación con los dos tipos fundamentales de interactividad que la mayoría de los investigadores distingue, aunque les otorga diversos nombres: la interactividad entre personas y la interactividad persona-máquina (Pereira, 2006: 175). A esos tipos de interactividad corresponderían los dos tipos fundamentales de interfaz: la interfaz gráfica de usuario (en inglés, GUI) y la interfaz ordenador-humano (Computer Human Interface, CHI). La más habitual es, desde que fue inventada por Xerox, empleada luego desde su inicio por los ordenadores Macintosh de Apple y más tarde popularizada por las sucesivas versiones de Windows (primero una interfaz, luego todo un sistema operativo) de Microsoft.

Desde una perspectiva igualmente semiótica, la profesora de la Universidad Católica de Milán (Italia), Nicoletta Vittadini, señala que la interacción -concepto del que proviene el de interactividad-se refiere a un tipo de acción que envuelve a varios sujetos, y que se caracteriza por la capacidad de cada sujeto de influir en las acciones de los otros, siendo cada acción la premisa para las realizadas posteriormente por los demás. Esto tiene una clara relación con las estrategias definidas en la teoría de juegos, que ya hemos examinado. La interacción, indica asimismo la investigadora italiana, se lleva a cabo respetando una serie de reglas (por lo que no es necesariamente igualitario; el grado de participación y colaboración está limitado por esas normas del juego) y debe ser capaz de provocar cambios en el contexto. Es lo que denomina reactividad, es decir, la capacidad de provocar reacciones. La diferencia que Vittadini, como otros autores, ve entre interacción e interactividad es que la primera es interpersonal y la segunda es mediada (Vittadini, 1995: 151, 154).

Lucía Santaella ve la interactividad como la acción que está "en la médula de los procesos cognitivos ensayados por la comunicación en ambientes informativos”, y la une con el dialogismo. 
Su concepto de diálogo bebe tanto de Bakhtin (es heteroglósico porque en todo enunciado de cualquier especie la interacción es uno de los fundamentos de la comunicación) como de Peirce (cuyo punto de partida está en la semiosis o la acción del signo, donde todo conocimiento es mediado) (Santaella, 2004: 151, 172).

Dada la importancia de esta característica del discurso digital, se hace necesario medir el grado de la misma. No hay unanimidad, sin embargo. Estudios como el de Ha y James, por un lado (Ha, James, 1998), y Neuberger, Tonnemacher, Biebl y Duck, por otro (Neuberger et al., 1998), concluían que, en aquel momento, los recursos interactivos no eran muy populares. Se trata, sin embargo, de la primera etapa del periodismo en Internet, por lo que, en los años que han transcurrido desde entonces, el modelo ha cambiado desde un mero volcado de contenidos y, por tanto, una traslación de los modelos del periodismo impreso al ciberperiodismo, hasta un discurso emancipado de los medios precedentes.

Otros autores -por ejemplo, la profesora brasileña de la Universidad de Santa María, Luciana Mielniczuk (Mielniczuk, 2001: 178)- también consideran que el cambio de paradigma introducido por los medios digitales revela las carencias de algunas dicotomías como la de medios interactivos y medios reactivos propuesta por Nicoletta Vittadini en 1995 (es decir, cuando la World Wide Web y el periodismo en Internet aún se hallaban prácticamente en mantillas), y ello porque dicha distinción puede, en su opinión, aplicarse al modelo tradicional de los medios de comunicación de masas (centralizados, de fuente única y audiencia dispersa), pero no al modelo rizomático de los medios en red, donde se producen situaciones que no se encuadran exactamente ni en una categoría ni en otra, y que, en todo caso, pueden calificarse de "interactividad de nivel bajo" o "reactividad compleja".

Para medir la interactividad, es cierto, se han propuesto diferentes criterios y métodos. Aquí expondremos los principales y, a nuestro juicio, más útiles para determinar hasta qué punto un sistema es interactivo. Así, B. Lauren proponía, en 1990, tres variables de la interactividad que podían ser observadas:

1) La frecuencia con que es posible interactuar con el sistema.

2) El campo de variabilidad: de cuántas opciones se dispone. 
3) Relieve: hasta qué punto las opciones influyen en la resolución de los problemas.

Por su parte, Pierre Lévy (Lévy, 1999: 79) presupone cinco grados de interactividad, que pueden ser analizados a partir de cinco ejes:

1) Posibilidades de apropiación y de personalización del mensaje.

2) Reciprocidad en la comunicación.

3) Virtualidad.

4) Implicación de la imagen de los participantes de los mensajes.

5) Telepresencia.

Nicoletta Vittadini (Vittadini, 1995: 56) propone una clasificación de la interactividad en niveles, a partir de tres criterios: el tiempo de respuesta, la calidad de los resultados y la complejidad del diálogo. Cuanto menor sea el tiempo de respuesta, mayor será el grado de interactividad; cuanto más complejo el sistema, mejor la calidad de los resultados; cuanto mayor sea la capacidad del sistema de simular las relaciones interpersonales, mayor el grado de interacción. Según estos criterios, el grado de interactividad se clasifica en tres niveles:

1) Baja complejidad: Sistemas basados en la selección de respuestas por parte del usuario mediante un menú de opciones.

2) Alta complejidad: Sistemas que tienen en cuenta las informaciones suministradas por los usuarios en momentos anteriores para proponerles nuevas situaciones y respuestas.

3) Complejidad intermedia: Sistemas que permiten la comunicación entre los usuarios a través del intercambio de mensajes.

Un texto de investigación que expone un método de análisis para medir la hipertextualidad y la interactividad de los cibermedios es el que presentó en 2003 Tania Oblak, de la Universidad de Ljubljana (Eslovenia), y que aplicó a una serie de medios de su país, los cuatro diarios más importantes. El punto de partida de Oblak es determinar hasta qué punto se hace uso de esas dos características que, como hemos visto, la mayoría de los investigadores aceptan como definitorias del mensaje digital, y comprobar si se está creando una nueva lógica mediática. 
Tania Oblak comparó las páginas o nodos iniciales de esos cuatro cibermedios. Distinguió entre enlaces internos y externos. La mayoría de las noticias que ofrecían enlaces lo hacían a otros ítems del propio medio. También midió la dependencia entre el tipo de medio y los enlaces hacia dentro o hacia fuera del mismo: cuanto más pequeño era el medio, es decir, cuanto menos contenido ofrecía, más enlaces externos proporcionaba. La conectividad entre contenidos propios era mayor, por otra parte, en aquellos medios con versión impresa y digital que en aquellos que sólo tenían versión digital.

En cuanto a la vertiente externa de la hipertextualidad, Oblak consideró dos variables: si un contenido de un medio se conectaba al de otro similar (de diario a diario, por ejemplo) o se prefería remitir a un medio de naturaleza distinta. En ambos casos, el porcentaje era muy bajo. El tamaño de la noticia no parecía tener ninguna influencia. La conclusión es que los enlaces externos son una característica de los cibermedios sin versión impresa o audiovisual previa.

Por lo que se refiere a la interactividad, Tania Oblak se fijó en la “distancia editorial” entre los diferentes tipos de medios. Se supone que un medio intenta reducir la distancia entre ese medio y los profesionales que lo hacen, por un lado, y los lectores, por otro, proporcionando recursos como las direcciones de correo electrónico de periodistas y editores. La distancia editorial era bastante grande en los medios estudiados, y sólo los medios puramente digitales proporcionaban esas direcciones de correo electrónico para facilitar el contacto directo con su público (OBlak, 2004).

Una metodología muy habitual es observar y describir cuáles son los servicios interactivos que determinados medios ofrecen. Es la que emplea, por ejemplo, José A. Lemos, investigador argentino, siguiendo al alemán Tanjev Schulz en un artículo publicado en el Journal of Computer Mediated Communication en 1999. Lemos enumera las siguientes opciones interactivas: direcciones generales de correo electrónico a las redacciones, direcciones de correos electrónicos a redactores o escritores, direcciones de correo electrónico a los autores de cada artículo, enlaces de correo electrónico a políticos y funcionarios de las administraciones públicas, foros de discusión, chats, sondeos y encuestas de usuarios, cartas al director, y servicios por correo electrónico (lista de titulares, alertas). En función de la presencia o ausencia de 
estos recursos en cada medio se obtuvo un nivel de interactividad que oscilaba entre "poca interactividad" a "alta interactividad" pasando por "media interactividad".

Una metodología similar se empleó dentro de la acción europea COST A20, sobre "El impacto de Internet en los medios de comunicación de masas". Cuatro investigadores de diferentes universidades del continente realizaron un estudio comparativo en sus respectivos países: Italia, Bulgaria, Estonia e Irlanda. Una de las investigadoras, Leopoldina Fortunati, explica de forma más detallada para el caso italiano la investigación sobre la interactividad de los diarios digitales de su país. Los cuatro investigadores distinguen tres aproximaciones a un concepto de por sí complejo: una, la aproximación comunicativa, referida sobre todo a los usuarios y las relaciones que establecen entre sí; la segunda, referida al entorno mediático, según la cual hay interactividad cuando los usuarios pueden modificar mediante su participación de forma instantánea la forma y los contenidos que ofrecen los medios (podría decirse que esta forma de interactividad es la personalización); y la tercera, es una aproximación a las relaciones de poder que subyacen en toda estructura comunicativa. Para medir el grado de interactividad de los diarios digitales de sus respectivos países, los cuatro investigadores se centraron en determinados rasgos de la página inicial de determinados diarios en Internet: direcciones de correo electrónicos, foros, cartas de los lectores, encuestas, chats, entrevistas de los lectores (Fortunati, 2005).

Una de las consecuencias de la interactividad -tanto en su vertiente técnica, de relación entre el sistema informático y el usuario, como en su vertiente de relación entre individuos- es o puede ser la personalización de la información. Ésta adquiere un aspecto diferente, un orden, una jerarquización, un tiempo de actualización y de remisión al usuario diferente según las preferencias expresadas por éste. Puede ser de varios tipos, desde el envío de una lista de titulares a la posibilidad de elección de idioma, pasando por una selección de las informaciones que el usuario quiere en un momento dado visualizar.

Se han dedicado algunas investigaciones a este aspecto concreto de la comunicación interactiva, la personalización. En 2005 se publicó en la Universidad del País Vasco la tesis de Mónica Ramírez Acevedo La relación del servicio de personalización de contenidos de las edi- 
ciones digitales de la prensa española y el mi-diario (en alusión al concepto de Daily Me o diario personalizado acuñado por Nicholas Negroponte en los primeros años de la década de 1990). La personalización es fruto tanto de la interactividad como de la modularidad impulsada por la concepción del diario digital como una base de datos (no sólo de noticias; también de datos de los usuarios, y de tráfico en general) que convierte a estos productos en "agentes de búsqueda de información”, muy en la línea de la empresa puntera durante la década de 2000 en la información digital: Google. Un concepto de "autoinformación” (self communication) que puede superar los paradigmas del periodismo informativo-interpretativo hasta ahora dominante, y que desarrolla el paradigma del periodismo de servicios. En el caso español, entre 2003 y 2004 ello se tradujo, según el estudio de Ramírez Acevedo, en la consolidación de las ediciones locales, posibilidad de modificación de la página de inicio y del tiempo, envío de contenidos previo registro gratuito al correo electrónico o la PDA, envío de alertas y recordatorios, servicio de navegación WAP para teléfonos móviles, envío de ofertas comerciales personalizadas, comercio electrónico y recogida de datos personales de los usuarios mediante formularios (Ramírez Acevedo, 2005a y b).

\section{La memoria}

La memoria es otra característica de la información digital que no todos los investigadores destacan, a pesar de su innegable importancia. De hecho, no faltan quienes vinculan precisamente la aparición del hipertexto a la necesidad de disponer de materiales relacionados cuyo volumen es tan inabarcable para la memoria humana que harían falta dispositivos externos para ayudarla.

Sí ha destacado el papel que la memoria cumple en el nuevo paradigma comunicativo Miquel de Moragas: "Los nuevos paradigmas deben centrar ahora su atención en la diversidad de las formas de acceso a las nuevas grandes memorias (digitales) de información por parte de los receptores" (Moragas, 2000).

La posibilidad de almacenar y poner a disposición del usuario grandísimas cantidades de información -aspecto de los sistemas multimedia en el que, junto con la interactividad, insiste 
Mariano Cebrián Herreros (Cebrián, 2005: 47)- más o menos estructurada de forma casi instantánea es un rasgo que distingue a la comunicación digital de otros tipos de comunicación que hasta ahora conocíamos. Este rasgo, que denominamos memoria, tiene importantes consecuencias en la forma del discurso periodístico.

Las redes de ordenadores traen consigo un fenómeno que podríamos denominar "memoria distribuida". En efecto, al romper la lógica de la presencia física del documento como condición sine qua non, se elimina igualmente la necesidad de la acumulación para pasar al efecto palimpsesto, en que las pantallas de borran y escriben de forma continua para traernos la información que demandamos, no importa dónde se encuentre. Se trata de un concepto cercano al de cognición distribuida del que habla Bernard Conein (Conein, 2004).

El concepto de memoria como inherente a la comunicación digital ha sido tratado por, al menos, dos autores. Uno de ellos es brasileño, Marcos Palacios, y el otro español, Antonio García Gutiérrez. Desde diferentes perspectivas, complementarias en todo caso. En este sentido, la reflexión de Marcos Palacios pone el acento sobre la memoria como elemento importante del nuevo mensaje informativo. La memoria tiene una influencia clara en la producción y en la recepción de ese mensaje informativo hipertextual (Palacios, 2002, 2003).

Una de las características de la memoria es que puede ser recuperada tanto por el productor como por el receptor. Se trata de una memoria múltiple, instantánea y acumulativa. Podría incluso tratarse de bancos de datos alimentados tanto por los productores como por los usuarios. En este sentido, los sistemas peer to peer (P2P) se han revelado como muy eficaces para la búsqueda e intercambio de información. Es lo que otros investigadores, como Tania Oblak, denominan archivality, como cuarta característica junto a la hipertextualidad, la multimedialidad y la interactividad.

Las metodologías de análisis propuestas para estudiar esta característica de la comunicación digital han sido varias. Por ejemplo, la perspectiva retórica es el instrumento principal que Michael Rinn propone para lo que denomina la "memoria corta de Internet" (Rinn, 2006). Parte del supuesto de que las propias características específicas de Internet hacen que los mediadores tradicionales de la memoria (familia, comunidades religiosas o instituciones 
científicas) se hayan visto sustituidos por una representación fragmentada de la realidad social (lo que siempre se ha dicho que hace el periodismo), hasta hacer poco menos que imposible los criterios de evaluación necesarios para la validación de la razón objetiva. Para remediarlo, Rinn propone un análisis retórico y acuñar nuevos conceptos semiológicos adaptados al nuevo medio caracterizado por la renovación constante de medios técnicos y de estrategias comunicativas.

La memoria tiene igualmente relación con la interactividad y, más en concreto, con la personalización, a la que ya hemos dedicado un epígrafe en el capítulo dedicado la interactividad. A la personalización dedicaron parte de su investigación Alberto Díaz, Pablo Gervás, Antonio García e Inmaculada Chacón. El punto de partida fue el análisis documental y la recuperación de la información. Estudiaron, por ejemplo, los robots de búsqueda, una de las herramientas más populares de Internet en la actualidad: indización, resúmenes, fórmulas de interrogación son algunos de los aspectos que investigaron. Junto con las estructuras hipertextuales subyacentes y en las cuales se materializan las búsquedas de información -lo que da lugar, según estos autores, a un nuevo modelo de recuperación de información- se estudió también la información pasiva, es decir, las alertas, las listas de titulares que se envían a los usuarios por correo electrónico a partir de perfiles de los usuarios previamente diseñados, los salvapantallas activos que aprovechan los momentos en que no está empleando el ordenador para conectarse a Internet y descargar información de temas predeterminados por el usuario. Hasta tal punto es importante el aspecto de la memoria en el ciberperiodismo, que los investigadores mencionados se plantean la existencia misma del discurso periodístico, tal como lo conocemos actualmente -una serie de reglas y estilos propios articulados en una serie de relatos- estaría en crisis. La nueva concepción del producto periodístico, y la concepción de otros agentes informativos, está mudando la forma en que las noticias se recuperan, se contextualizan y se producen en el medio digital. La importancia de los lenguajes documentales, y su relación con el hipertexto, debe ser incorporada a la enseñanza y el estudio de las técnicas periodísticas (Díaz et al., 2000).

La adopción de la memoria como una de las características de la comunicación digital tiene implicaciones narratológicas, como ha puesto de manifiesto Lev Manovich (Manovich, 2005: 
282, 295). La tradicional división entre narración y descripción se desdibuja precisamente por la abundancia de información en forma de datos. Manovich habla incluso de lógicas opuestas de las bases de datos y las narraciones. Parte de un supuesto, sin embargo, que consideramos superado, y que toma, sin nombrarlo, de Thomas Hobbes: que el hablante construye su expresión en forma de secuencia lineal.

\section{Multimedialidad}

La multimedialidad es una de las características menos estudiadas, tal vez por menos desarrolladas, del nuevo lenguaje digital. A pesar de que habitualmente se ha insistido en que son la hipertextualidad y la interactividad los rasgos más destacados de la edición digital, no falta quien pone más bien el acento en la multimedialidad. Por ejemplo, Kathleen Burnett, para quien lo que distingue el hipermedia de otros modos de información no es que esté gobernado por la tecnología informática, ni que sea interactiva, ni que incluya aparatos de navegación a través de nodos e hipervínculos, ni la especificidad de su estructura reticular e interactiva. Lo que distingue al hipermedia, según esta autora estadounidense, es que constituye una estructura informativa muy diferente de cualquier otra, que debe ser contemplada con todos sus rasgos de forma global (Burnett, 1993). Como recuerdan Bettetini, Gasparini y Vittadini, el discurso multimedial no es sólo un producto tecnológico, sino que su característica central es la intervención del lector. Definen así la multimedialidad como "la integración informática de varios medios o códigos expresivos en el interior de un mismo texto". Siguen así, de alguna manera, a Deleuze y Guattari en su concepto del rizoma (Deleuze y Guattari, 2005).

Nicholas W. Jankowski y Lucien Hanssen, en su libro The contours of multimedia, hicieron un repaso por las diferentes definiciones del término. Para Jankowski y Hanssen, la mejor definición es aquella que ha encontrado mayor consenso, desde el punto de vista técnico, como "integración digital de diferentes tipos de medios dentro de un único sistema tecnológico" (Jankowski et al., 1996). 
Sólo unos pocos autores prefieren definir el multimedia desde el punto de vista del usuario. En ese mismo libro coordinado por Jankowski y Hanssen, Cees Leeuwis critica las definiciones técnicas por considerar que no son capaces de describir y predecir adecuadamente el comportamiento de los medios y las características del usuario. Para Leeuwis, se trata de una visión más bien mecánica de la comunicación multimedial. Por el contrario, prefiere una aproximación centrada en la interacción, donde los procesos comunicativos se contemplan como procesos de negociación (Leeuwis, 1996).

Otros autores definen la multimedialidad desde el punto de vista del lenguaje y la semiótica. La profesora brasileña Lucía Santaella explica que el primer rasgo es la hibridación de lenguajes, y cuando se hibrida además con la tecnología, se habla de convergencia de medios. El segundo rasgo es la organización reticular de los flujos informativos en arquitecturas hipertextuales. Finalmente, dice Santaella, es un lenguaje fundamentalmente interactivo (Santaella, 2004: 48).

La definición del término "multimedia" se ubica, según investigadores teóricos como Carlos Colina o Michel Miradito (Colina, 2002: 48), en un plano descriptivo, ya que generalmente se presenta como una "combinación e integración" de diversos medios y tipos de información: textual, icónica, sonora, datos... Se trataría de la "descripción de una realidad emergente".

Mariano Cebrián insiste en la tendencia convergente del concepto de multimedialidad (Cebrián, 2005: 17). También, como anteriormente habían hecho Díaz Noci y Salaverría (2003), en la necesidad de que, para que un mensaje pueda ser considerado realmente multimedia, los diferentes lenguajes no estén meramente yuxtapuestos, sino que se trate de una verdadera integración de lenguajes. Todos ellos presentados en el marco de un encuadre rectangular. La pantalla es no sólo una superficie; es también una interficie, un término acuñado por Antonio Rodríguez de las Heras: "La interficie es el lugar de contacto entre los dos espacios [...]. La forma de trabajar la interficie da como resultado una interfaz" (Rodríguez de las Heras, 2001). El hipermedia significa poder concentrar una gran cantidad de información, lo que hace preciso el desarrollo de mapas cognitivos que se materializan en guiones de navegación. 
La lectura hipermedial es, para Lucía Santaella, conmutable entre varios niveles mediáticos. Tiene un efecto centrífugo, porque el enlace invita al lector a dar un salto receptivo entre varios fragmentos o planos, mediante una lógica asociativa, que se concreta en mapas cognitivos personalizados e intransferibles, mapas "semióticos rizomáticos". Es también una lectura topográfica.

Las modalidades de lectura tienen también que ver con los aspectos psicológicos del hipermedia. Por ejemplo, con el denominado horizonte de expectativas del que habla la teoría de la recepción. Toda teoría del texto es una teoría de la lectura, según Umberto Eco, donde se combinan los rasgos de intertextualidad y estructura con los de infinitud y apertura, que nos resultarán familiares después de los capítulos que hemos dedicado a la hipertextualidad. De ahí se llegaría al concepto de gramática narrativa. La narratividad y la forma de lectura en el ciberespacio, muchas veces -y cada vez más- deudora de la lógica estructural de las bases de datos, puede explicarse recurriendo precisamente al concepto de exploración.

Aunque estén relacionadas, conviene distinguir entre las modalidades de lectura, que hacen referencia más bien a las habilidades cognitivas del lector y a sus objetivos concretos cuando se enfrenta a la búsqueda de información, y las modalidades de navegación, que se refieren a la estructura del hiperdocumentos y a las posibilidades que el autor y el sistema ofrecen al lector para moverse por entre los ítems informativos. Entre las tipologías de navegación, Xosé Pereira distingue la abierta, la lineal y la circular, donde "el discurso informativo termina donde empieza" (Pereira, 2006: 171).

Una distinción pertinente, nos parece, en esta fase del ciberperiodismo en que nos encontramos, es la que divide los sitios web en dinámicos y estáticos. Como recuerda Manuel Gago, los estáticos sólo pretenden reproducir "directamente las condiciones de lectura de un periódico en formato papel”, con una linealidad básica "únicamente rota por embrionarios experimentos de hipertextualidad interna y externa”, donde el principal factor diferenciador entre la versión impresa y digital de, por ejemplo, un diario, se encuentra en la navegación mediante menús e índices, en opinión del investigador gallego (Gago, 2006: 97). 
Por el contrario, los sitios dinámicos responden a las necesidades planteadas por un aumento en el volumen de la información, como se detalla en el capítulo dedicado a la memoria y la gestión de la información, y por los diferentes lenguajes de los ítems informativos empleados: sonidos, textos, infografías, imágenes, etc., que hicieron necesario su organización en bases de datos interactivas y el etiquetado de dichos ítems. Si en un sitio estático, dice Gago, la relación entre forma y contenido es de 1-1, en uno dinámico es de $n$ a $n$, ya que los ítems informativos pueden virtualmente presentarse con cualquier tipo de relación entre ellos y en diversas formas. Parte del trabajo se establece en forma de rutinas automáticas que, en base siempre a los criterios establecidos por los humanos, el sistema es capaz de desarrollar.

En cuanto a los métodos de evaluación de la multimedialidad, Mariano Cebrián Herreros propone, al final de su libro Información multimedia, un sistema de evaluación de los sistemas multimedia, inspirado en el empleado por el Festival Audiovisual y Multimedia de Biarritz (Francia):

- Calidad de pantallas

- $\quad$ Calidad de interactividad.

- $\quad$ Valores estéticos.

- $\quad$ Calidad del diálogo entre el hombre y el sistema informático.

- Calidad técnica de concepción y realización.

- $\quad$ Facilidad de manejo.

- $\quad$ Pertinencia de la elección de la configuración en relación con el objetivo de la información.

Esta evaluación, cuyos apartados se valoran en todos los casos con hasta 5 puntos, tiene el problema de que la mayoría de los criterios son demasiado subjetivos.

Otros sistemas de evaluación proponen pruebas mensurables. Boyle, Hor Teh y Williams (1991), por ejemplo, plantean una prueba basada en la creación de nodos y enlaces entre ellos (un método autorial) y un método para medir la efectividad del rastreo en varios sistemas de 
hipermedia. Otros, como S. Shyam Sundar (Sundar, 2000), se fijan en los efectos de la multimedialidad en el procesamiento y percepción de noticias en Internet, especialmente aquellas que se presentan en formato sonoro o visual. Sundar se pregunta si las propiedades multimediales afectan a la recepción de las informaciones periodísticas y si la descarga de archivos de sonido e imagen producen una impresión positiva del sitio web del medio que los ofrece. Para medirlo, propone un experimento basado en cinco condiciones. Cada participante del experimento leyó tres noticias de un sitio web creado al efecto: una versión sólo con texto, otra con texto e imágenes, otra con texto y sonidos, otra con texto, sonido e imágenes, y una quinta con texto, sonido y vídeo. Se trataba de medir la retención y percepción, mediante las siguientes nueve variables que se pedía a los participantes que valorasen:

- $\quad$ Retención de la noticia.

- $\quad$ Reconocimiento de la noticia.

- $\quad$ Retención de anuncios publicitarios.

- Reconocimiento de asunciones publicitarios.

- $\quad$ Diseño del sitio web.

- $\quad$ Coherencia.

- $\quad$ Intentos de volver a visitar el sitio web.

- $\quad$ Calidad de la noticia.

- Credibilidad de la noticia.

El resultado del experimento fue que las imágenes y el sonido son particularmente potentes desde un punto de vista psicológico, aunque, mientras que el multimedia refuerza la retentiva de contenidos noticiosos, provoca evaluaciones negativas del sitio web, probablemente porque la descarga de archivos visuales o sonoros penaliza el tiempo de lectura.

También emplean una base cognitivista Peter Faraday y Alistair Sutcliffe (Faraday, Sutcliffe, 1997). Para medir las presentaciones multimediales, ambos investigadores británicos se fija- 
ron en la atención, el foco temático y los tipos de información para practicar varios estudios empíricos. Uno de ellos, más bien referido al diseño, se refiere a la ruta ocular, algunos años antes que los primeros estudios Eyetrack del Poynter Institute. Nos interesa más una serie de estudios de comprensión que buscaban determinar la efectividad de una presentación multimedial. El método empleado fue:

1) Evaluar la atención prestada al diseño, especialmente fijándose en la secuencia seguida y en el tiempo empleado. Para evaluar la atención prestada al diseño se dividió la presentación en unidades constituyentes, tanto lingüísticas (texto) como visuales (fotografías o animaciones), ordenadas en un gráfico temporal. Se intentó trazar un mapa de los movimientos que los usuarios desarrollaban en la lectura de la información.

2) Evaluar los puntos de contacto, aquellos donde se fija la atención del lector. Cuando se combina información verbal y visual, dicen Faraday y Sutcliffe, el mensaje se sigue gracias a determinados puntos de contacto, que deben ser identificados. Habitualmente, en un sistema hipermedial son hipervínculos, cuya activación debe ser síncrona entre los diferentes tipos de información.

3) Evaluar la selección de los tipos de información y su combinación, es decir, tanto los mapas mediante los cuales se estructura la información y si los medios usados son apropiados. Esto tiene que ver con los contenidos temáticos de la presentación multimedia comparados con el texto original que está en la base del producto multimedia. Se trata de determinar qué tipos de lenguaje se emplean, cuál es su disposición física y especial, cuáles las acciones que proponen y cuál el procedimiento de la(s) secuencia(s) propuesta(s).

No hay que olvidar que la coherencia global no sólo depende de la estructura semántica, sino también de la coherencia pragmática que le asigna el lector. Buena parte del concepto de coherencia y cohesión, como el de isotopia de Greimas, se basa en la existencia de reglas como la redundancia, la reiteración y la repetición, es decir, la iteratividad. Aún más en un cibertexto: mediante las combinaciones hipertextuales, es posible proponer al lector diversos itinerarios. Cuáles y cómo sigue el lector esos itinerarios, y por qué, es una de las preguntas fundamentales de la investigación sobre la lectura del hipermedia. 


\section{Referencias bibliográficas}

Aarseth, E. (1997a): Cybertext: Perspectives on Ergodic Literature, Baltimore; London: The Johns Hopkins University Press.

Aarseth, E. (1997b): “No sense of an ending: hypertext aesthetics”, en Cyberperspectives on ergodic literature, Baltimore; London: The John Hopkins University Press, p. 76-96.

Aarseth, E. (2003): The hypertext revolution http://www.educ.fc.ul.pt/hyper/resources/eaarseth.htm.

Bal, M. (1998): Teoría de la narrativa (una introducción a la narratología), Madrid: Cátedra.

Bettetini, G.; Gasparini, B.; Vittadini, N. (1999): Gli spazi dell'ipertesto, Milano: Bompiani.

Boyle, C.; Hor The, S.; Williams, C. (1990): “An empirical evaluation of hypertext interfaces”, Hypermedia, vol. 2, n. 3, pp. 235-247.

Burnett, K. (1993): “Toward a theory of hypertextual design”, Postmodern Culture, vol. 3, nº 2 http://www3.iath.virginia.edu/pmc/text-only/issue.193/burnett.193.

Carvalho, M. (2005): "Mapeamento e produçao de sentido: os links no hipertexto", en Marcuschi, A.; Xavier, A. C. Hipertexto e gêneros digitais, Rio de Janeiro: Lucerna.

Cebrián Herreros, M. (2005): Información multimedia. Soportes, lenguaje y aplicaciones empresariales, Madrid: Pearson.

Clément, J. (1995): “Du texte à l'hypertexte: vers une épistémologie de la discursivité hypertextuelle”, en Balpe, J.-P.; A. Lelu; I. Saleh (coords.). Hypertextes et hypermédias: Réalisations, poutils, methods, París: Hermès http://hypermedia.univ-paris8.fr/jean/articles/discursivité.htm.

Codina, L. (2002): “Información documental e información digital”, en López Yepes, J. (coordinador): Manual de Ciencias de la Documentación, Madrid: Pirámide, pp. 301-316.

Colina, C. (2002): El lenguaje de la red. Hipertexto y posmodernidad, Caracas: Universidad Católica Andrés Bello. 
Conein, B. (2004): “Cognition distribuée, groupe social et technologique cognitive”, Réseaux, no 124 , pp. 53-79.

Crystal, D. (2001): Language and the Internet, Cambridge: Cambridge University Press.

Cunliffe, D. (2000): “Trailblazing: trends in hypermedia”, The New Review of Hypermedia and Multimedia, pp. 19-46.

Dee-Lucas, D. (1996): "Effects of overview structure on study strategies and text representations for instructional hypertext”, en Rouet, J.F.; Levonen, J. J.; Dillon, A.; Spiro, R. J. (eds.). Hypertext and cognition, Mahwah, NJ: Lawrence Erlbaum.

Deleuze, G.; Guattari, F. (2005): Rizoma (Introducción), Valencia: Pre-Textos.

Deuze, M. (2001): "Online journalism. Modelling the first generation of news media on the World Wide Web”, First Monday. Vol. 6, n. 10, October, http://firstmonday.org/issues/issue6_10/deuze/index.html.

Díaz Noci, J. (2002): “El juego de la información. Tecnología del hipertexto, teoría de juegos y su aplicación en el periodismo”. Comunicación presentada al VII Congreso de la Sociedad Española de Periodística, Sevilla, 7-9 de marzo de 2002 http://www.ehu.es/diaz-noci/Conf/C21.pdf.

Díaz Noci, J.; Salaverría Aliaga, R. (coords.) (2003): Manual de redacción ciberperiodística, Barcelona: Ariel.

Díaz, A.; Gervás, P.; García, A. (2000): “Evaluationg a user-model based personalisation architecture for digital news services”, en Borbinha, J.; T. Baker (eds.), ECDL 2000. Berlín: Springer-Verlag, p. 259-268.

Domingo, D. (2006): Inventing online journalism. Development of the Internet as a news médium in tour Catalan online newsrooms. Tesis doctoral presentada en la Universitat Autònoma de Barcelona. 
Echeverría, J. (2002): “Las telecomunicaciones, un nuevo espacio para la escritura y publicación electrónica”, en LaMusa, $\mathrm{n}^{\mathrm{O}} \quad 0$ http://www.uclm.es/ab/humanidades/lamusa/paginas/monografico/echevarria.ht.

Eco, U. (1968): La struttura assente. Milano: Bompiani, 1968 (traducción española: La estructura ausente. Introducción a la retórica. Barcelona: Lumen, 1999, p. 19-21.

Eco, U. (19771, 1988): Tratado de semiótica general, Barcelona: Lumen.

Engebretsen, M. (2001): Nyheten som hypertekst. Tekstuelle aspekter ved motet mellom en gammel sjanger og ny teknologi, Oslo: Norwegian Academic Press.

Engebretsen, M. (1997): “Hyper-news: revolution or contradiction?”, Hypertext 97, Southampton: ACM, pp. 222-223.

Faraday, P.; Sutcliffe, A. (1997): "Evaluating multimedia presentations", The New Review of Hypermedia and Multimedia, 1997, pp. 7-37.

Fiormonte, D. (2002): “Sobre el problema de la filología digital”, LaMusa, no 0 http://www.uclm.es/ab/humanidades/lamusa/paginas/monografico/Fiormonte.htm.

Fiormonte, D.; Cremascoli, F. (1998): Manuale di scrittura, Torino: Bollati Boringhieri.

Fortunati, L. (2005): “Forme d'interattività. Un'indagine sui quotidiani online in Itália”, Problema dell'Informazione, anno xx, no 1, marzo, pp. 89-113.

Fortunati, L.; Raycheva, L.; Harro-Loit, H.; O’Sullivan, J. (2005): “Online news interactivity in tour European countries: a pre-political dimension”, en Masip, P.; Rom, J. (eds.). La utopia digital en els mitjans de comunicació: dels discursos als fets. Un balanç. Barcelona: Universitat Ramon Llull, pp. 417-430;

Gago, M. (2006): “La arquitectura de la información, ingeniería del periodismo”, en López, Xosé (coord.). Sistemas digitales de información, Madrid: Pearson.

Ha, L.; James, E.L. (1998): "Interactivity reexamined: a baseline analysis of early business Web sites”, Journal of Broadcasting \& Electronic Media, 42/4, pp. 456-474. 
Hanssen, L.; Jankowski, N.; Etienne, R. "Interactivity from the perspective of communication studies”, en Jankowski, N.; Hanssen, L. (eds.): The contours of multimedia. Recent technological, theoretical and empirical developments, Luton: University of Luton Press, pp. 61-73.

Lauren, B. (1990): The art of human-computer interface design, Reading, MA: Addison-Wesley.

Leeuwis, C. (1996): “Communication Technologies for information-based services: experiences and implications”, en Jankowski, N.; Hanssen, L.: The contours of multimedia. Recent technological, theoretical and empirical developments, Luton: University of Luton Press, pp. 86-102.

Lévy, P. (1999): Cibercultura, São Paulo: Editoria 34.

López García, X.; Gago Mariño, M.; Pereira Fariña, J. (2002): Novas tendencias do xornalismo electrónico, Santiago de Compostela: Edicións Lea.

López García, Xosé; Gago Mariño, Manuel; Pereira Fariña, José. O novo xornalismo electrónico. Santiago de Compostela: Edicións Lea, 2000;

López, X. et alii (2005): "Medios digitales de Galicia: ¿versiones de los diarios impresos o cibermedios?", en VII Congreso de la Sociedad Española de Periodística. Santiago de Compostela: Universidade de Santiago de Compostela, pp. 616-636.

Lozano, J.; Peña-Marín, C.; Abril, G. (1989): Análisis del discurso. Hacia una semiótica de la interacción visual, Madrid: Cátedra.

Machado, E. (2003): O ciberespaço como fonte para os jornalistas, Salvador de Bahia: Calandra.

Machado, E.; Borges, C.; Miranda, M. (2004): "Gêneros narrativos em el periodismo digital baiano", Sala de Prensa. Año 5, vol. 2, n. 63.

Maietti, M. (2004): Semiotica dei videogiochi, Milano: Unicopi.

Manovich, L. (2005): El lenguaje de los nuevos medios de comunicación, Barcelona: Paidós.

Marcuschi, L. A. (1999): "Linearizaçâo, cogniçâo e referência: O desafio do hipertexto”, en Línguas, instrumentos lingüísticos, Campinas: Pontes, p. 21-46. 
Marcuschi, L. A. (2000): “A coherencia no hipertexto”, en I Serimário sobre Hipertexto, Recife: Centro de Artes e Comunicaçâo.

Mielniczuk, L. (2001): “Considerações sobre interatividade no contexto das novas mídias”, en Lemos, A.; Palacios, M. (orgs.): Janelas do ciberespaço. Comunicação e cibercultura, Porto Alegre: Sulina.

Moragas, M. (2005): "Cambios en la comunicación, cambios en los estudios de comunicación”, Signo y Pensamiento, vol. xxiv, no 47, julio-diciembre, pp. 9-20.

Moreno, I. (2002): “Musas y nuevas tecnologías. El relato hipermedia”, Barcelona: Paidós.

Moulthrop, S. (1997): "Pushing back: Living and writing in broken space", en Modern Fiction Studies, vol. 43, n. 3 http://iat.ubalt.edu/moulthrop/essays/pushMe.html.

Neuberger, C.; Tonnemacher, J.; Biebl, M.; Duck, A.: “Online- The Future of Newspapers? Dailies on the World Wide Web”, Journal of Computer Mediated Communication, 4/1 http://www.ascusc.org/jcmc/vol4/issuel/neuberger.html.

Oblak, T. (2004): "Aspects of cyber-textuality: interactivity and hypertextuality of online media", en Salaverría, R.; Sádaba, C. (eds.): Towards new media paradigms. II International Conference of COST A20, Pamplona: Eunate, pp. 137-150.

Pajares Tosca, S. (2003): ¿Qué fue del hipertexto? http://jamillan.com/celtos.htm.

Palacios, M. (2002): “Jornalismo online, informação e memória: apontamentos para debate”, Comunicação apresentada nas Jornadas de Jornalismo Online, 21-22 de junho de 2002, Departamento de Comunicação e Artes, Universidade da Beira Interior http://www.bocc.ubi.pt.

Palacios, M. (2005): "Natura non facit saltum: Promesas, alcances e limites do desenvolvimento do jornalismo on-line e da hiperficção", e-COMPOS. Revista eletrônica da COMPÓS, vol 1, no 2, Brasília.

Palacios, M. (2003): "Ruptura, continuidade e potencialização no jornalismo on-line: o lugar da memória”, en Machado, E.; Palacios, M. (org.): Modelos de jornalismo digital, Salvador de Bahia: GJOL; Calandra, pp. 13-36. 
Pereira, X. (2006): “La presencia gráfica del sistema (front-end)”, en López, X. (coord.). Sistemas digitales de información, Madrid: Pearson.

Powell, T. A. (2001): Diseño de sitios web, Madrid: McGraw-Hill.

Rada, R.; Murphy, C. (1992): “Searching versus browsing in hypertext”, Hypermedia. Vol. 4, n.1, pp. 1-30.

Ramírez Acevedo, M. (2005a): “La personalización de contenidos de ls ediciones digitales de la prensa española, como apuesta por los gustos y preferencias del internatura en un mercado global”, en La comunicación local por Internet. IV Congreso de Comunicación Local (ComLoc 2004), Castelló de la Plana: Publicacions de la Universitat Jaume I, pp. 381-390.

Ramírez Acevedo, M. (2005b): La relación del servicio de personalización de contenidos de las ediciones digitales de la prensa española y el mi-diario, Bilbao: Servicio Editorial de la Universidad del País Vasco.

Rinn, M. (2006): "La mémoire courte de l'Internet. Analyse sémiodiscursive du den de la Shoah”, Communication \& Langages, 137, mars, pp. 73-85.

Rodríguez de las Heras, A. (1991): Navegar por la información, Madrid: Fundesco.

Rost, A. (2006): La interactividad en el periódico digital, Tesis doctoral presentada en la Universitat Autònoma de Barcelona.

Rovira, C. (2002a): “Estructuras de navegación para e-learning”, El profesional de la información, vol. 1, núm. 6, novembre-desembre, pp. 457-466;

Rovira, C. (2002b): "Hypertext representation for education and learning”, Interactive Educational Multimedia, núm. 5.

Royo, J. (2004): Diseño digital, Barcelona, Paidós.

Ryan, M.-L. (2004): La narración como realidad virtual. La inmersión y la interactividad en la literatura y en los medios electrónicos, Barcelona: Paidós. 
Sádaba Chalezquer, M. R. (2000): "Interactividad y comunidades virtuales en el entorno de la World Wide Web”, Comunicación y Sociedad, vol. xiii, nº 1, Pamplona: Universidad de Navarra, pp. 139-166.

Santaella, L. (2004): Navegar no ciberespaço. O perfil cognitivo do lector imersivo, São Paulo: Paulus.

Scolari, C. (2000): "Por un puñado de hiperlibros. Interactive fiction, narrativa y retórica hipertextual”. Ponencia presentada en el xxviii ${ }^{\circ}$ Congreso de la AISS (Associazione Italiana Studi Semiotici), Castiglioncello, 6-8 ottobre 2000. http://www.modernclicks.net/htxt_scolari1.html.

Scolari, C. (2003): Hacer clic. Hacia una sociosemiótica de las interacciones digitales, Barcelona: Gedisa.

Soojung-Kim Pang, A. (1998): "Hypertext, the next generation: A review and research agenda”, First Monday.Vol. 3, n. 11, http://www.firstmonday.dk/issues/issue3_11/pang/index.html.

Sundar, S. S. (2000): "Multimedia effects on processing and perception of online news: A study of picture, audio, and video downloads”, Journalism \& Mass Communication Quarterly, vol. 77, n. 1, Autumn, p. 480-499.

Toschi, L. (a cura di) (2001): Il linguaggio dei nuovi media. Web e multimedia: principe e tecniche delle nuove forme di comunicazione, Milano: Apogeo.

Vianello Osti, M. (2004): El hipertexto entre la utopía y la aplicación: identidad, problemática y tendencias de la Web, Gijón: Trea.

Vilariño Picos, M. T.; Abuín González, A. (2006): Teoría del hipertexto. La literatura en la era electrónica, Madrid: Arco/Libros.

Vittadini, N. (1995): “Comunicar con los nuevos media”, en Colombo, F. (ed.): Las nuevas tecnologías de la información, Barcelona: Anagrama. 
